\title{
LA COMUNICACIÓN EN LA VIRTUALIZACIÓN DE LA EDUCACIÓN. EL CASO EL CAMPUS VIRTUAL PUNTOEDU
}

\author{
María Cristina Alberdi (UNR)*
}

\section{Resumen}

Las experiencias educativas que incorporaron soportes informáticos dieron origen a lo que se ha denominado educación virtual, en donde los modos de aprendizaje, la organización del tiempo y del espacio de estudio resultan diferentes a los que se utilizaban en la educación tradicional. Estos entornos adoptan, en mucho de los casos, las figuras de "Campus virtual" y "Aula Virtual" que propician situaciones educativas que posibilitan la construcción social de conocimiento en el que el alumno cuenta con la posibilidad de una constante interacción con el docente y los compañeros, permitiendo que el aprendizaje sea un trabajo activo de comunicación, investigación e intercambio de información.

En este artículo se propone reflexionar particularmente, sobre los modos de comunicación e interactividad que propician nuevas relaciones temporo-espaciales en el estudio de caso de la experiencia educativa en las aulas virtuales del Campus Virtual de la U.N.R., Puntoedu.

\section{Palabras clave}

Educación virtual - Comunicación - TIC - Virtualidad - Entornos virtuales de aprendizaje.

\begin{abstract}
Educational experiences that incorporate computer media gave rise to what has been called virtual education, where learning styles, organization of time and space for study are different from those used in traditional education. These environments take, in many cases, the figures of "virtual campus" and "Virtual Classroom" to foster educational situations that enable the social construction of knowledge in which the student has the possibility of a constant interaction with the teacher and peers, allowing learning to

* Magister en Ciencias de la Comunicación. Centro de Estudios en Cultura y Tecnología. Universidad Nacional de Rosario. Licenciada en Comunicación Social. Facultad de Ciencia Política y RR. II. Universidad Nacional de Rosario.
\end{abstract}


be an active work of communication, research and information exchange. This article focuses particularly on modes of communication and interaction that encourage new temporo-spatial relationships in the case study of the educational experience in virtual classrooms Virtual UNR Campus, PuntoEdu.

\section{Key words}

Virtual education - Communication - Virtuality - Virtual learning environments.

\section{La comunicación en la virtualización de la educación. El caso del Campus Virtual Puntoedu}

Las experiencias en instituciones de educación formal y no formal que incorporaron soportes informáticos dieron origen a lo que se ha denominado educación virtual, en donde los modos de aprendizaje, la organización del tiempo y del espacio de estudio resultan diferentes a los que se utilizaban en la educación tradicional. Estos entornos adoptan en mucho de los casos las figuras de "Campus virtual" y "Aula Virtual" que propician situaciones educativas que posibilitan la construcción social de conocimiento en el que el alumno cuenta con la posibilidad de una constante interacción con el docente y los compañeros permitiendo que el aprendizaje sea un trabajo activo de comunicación, investigación e intercambio de información.

Las universidades al igual que otras instituciones educativas se han visto afectadas de diferentes modos debido a la incorporación de las TIC, dando lugar a transformaciones en sus estructuras y funciones, como seguramente pueden reconocerla en muchas de las actividades cotidianas de su vida académica. Esta virtualización en forma parcial o total está relacionada con actividades educativas, de investigación y gestión, administración a través de Internet, tales como aprender mediante la interacción en cursos electrónicos, inscribirse en un curso, consultar documentos en una biblioteca electrónica, comunicarse con estudiantes y profesores.

La conformación de espacios virtuales educativos implica una reconfiguración del sistema de enseñanza en su conjunto que incide en los sujetos y en el proceso de aprendizaje, como así también en la organización y en las estrategias de intervención pedagógico-didáctica posibilitando la articulación de herramientas que organizan el mundo material, herramientas conceptuales y cognitivas utilizadas para la organización de la información y herramientas socioeconómicas o institucionales promoviendo cambios en la sociedad. De este modo se ha ido produciendo la modificación de los sistemas tradicionales de enseñanza, puesto que evidencian la ruptura de la triple unidad -vigente durante siglos- de la enseñanza basada en la convergencia de lugar, tiempo y acción. Según afirma Pierre Levy (1990:20) lo virtual es intangible, carece 
de materialidad; en otras palabras: "no está ahí", no está en ningún lugar, no tiene territorio, pero están sus marcas, sus huellas digitales que marcan los recorridos, los itinerarios, las relaciones.

En el diseño de entornos virtuales se considera como uno de los objetivos a lograr, la superación de los límites espacio-temporales a partir de creaciones de ambientes que simulan modos de comunicación similares a los que se dan en la educación presencial tradicional. En dichos ambientes, denominados campus virtuales, aulas virtuales, pupitres virtuales, etc., los docentes, alumnos y tutores, trabajan e interactúan a través de recursos integrados: presentación de clases o contenidos, charlas en tiempo real (chat), o comunicaciones en tiempo diferido (correo electrónico, foro de debates, herramientas de evaluación y autoevaluación, calendario, pizarras), y otras herramientas que dependen de la plataforma en particular.

En este artículo se propone una reflexión sobre los modos de comunicación e interactividad que propician nuevas relaciones temporo-espaciales en los entornos virtuales. Con tal fin se presenta el análisis del estudio de caso de la experiencia educativa en las aulas virtuales del Campus Virtual de la U.N.R., Puntoedu. La experiencia inicia su proceso de construcción en abril de 2000; en la primera fase se propuso generar la infraestructura necesaria para llevar adelante una modalidad de enseñanza mediante entornos virtuales que se articule con la enseñanza tradicional de la institución universitaria.

En el año 2002 comienza el desarrollo de una plataforma en base a un producto existente de código abierto construida originalmente por la Universidad de Colonia en Alemania. El diseño de la plataforma implica cuestiones sumamente interesantes desde el punto de vista comunicacional, pedagógico y en el modo en que se propician la creación de espacios que posibiliten la construcción del conocimiento mediatizado por las redes digitales.

En el caso de Puntoedu, la conformación del Campus Virtual con las Aulas Virtuales constituye el entorno en el que se conjugan las coordenadas temporo-espaciales dando origen a un ambiente de encuentro entre educadores y educandos para realizar actividades que promueven el aprendizaje. Este espacio, en donde se actualizan las actividades involucradas en el proceso de enseñanza y aprendizaje, se produce la interactividad entre docentes, alumnos y contenidos, la coordinación de las tareas de la clase, la aplicación de los conocimientos, los procesos de evaluación. Las herramientas de comunicación hacen posible el encuentro, establecer diálogos en tiempo real a través del chat o comunicarse de modo asincrónico mediante el correo o el foro; no se limita a ser un lugar de almacenamiento y distribución de contenidos.

El entorno virtual de aprendizaje se caracteriza por la desterritorialización debido a la separación de las coordenadas espacio-temporales representativas de la modernidad. La virtualización plantea unidad de tiempo sin unidad de lugar, posibilitado por las interacciones en tiempo real a través de redes electrónicas, 
a las retransmisiones en directo, a los sistemas de telepresencia, factores que permiten una continuidad de acción a pesar de la duración discontinua, la sincronización reemplaza la unidad de lugar y la interconexión sustituye la unidad de tiempo (Levy, 1990:22). Este entorno configura mundos basados en el uso de lenguaje hipertextual que se crea a partir de la actividad colectiva en tiempo real y conforman metáforas a modo de representaciones de espacios y prácticas educativas tradicionales, que ofrecen modelos que permiten aprehender, interactuar, conformar una comunidad de conocimiento.

Una de las dimensiones para poder comprender la virtualización en cuanto a la comunicación, es analizar los modos de construcción del sujeto discursivo en los textos de Puntoedu.edu.ar, si bien se debe aclarar que no pretende constituirse en un análisis del discurso de textos educativos, sino de pensar la forma en que éstos son construidos para establecer una relación dialógica mediatizada a través de una tecnología digital. En la producción de estos discursos se intenta superar los límites de tiempo y de espacio, configurar una comunidad virtual cuyo fin principal es propiciar aprendizajes relevantes, favoreciendo además el encuentro entre alumnos y docentes en la formación en distintas disciplinas.

El análisis documental permite reconocer que la propuesta de educación virtual del Campus supone un proceso de producción de sentido, un proceso de resignificación constante, donde se intercambian los roles discursivos, diferenciándose de la educación a distancia tradicional que privilegia el diseño de contenidos y materiales. La concepción educativa es considerada desde una perspectiva constructivista, en el cual el docente se plantea, no como depositario del saber sino como un sujeto que acompaña el/los recorridos diferentes de los alumnos, presenta nuevos y verdaderos desafíos para pensar esta problemática. En este contexto educativo se establece un "Contrato" que permite un pacto o convenio entre los sujetos que interactúan en el proceso educativo. Arfuch (1999:44), señala al respecto que:

"La noción de contrato fue definida en el marco de la semiótica greimasiana como una distinción intuitiva para aludir a una relación intersubjetiva que se establece en todo proceso comunicativo, al intercambio que, según ciertas reglas, se da entre los participantes, estableciendo una especie de "obligación mutua" (...). La noción de contrato de lectura remite a ciertas pautas que, en el marco de un género discursivo determinado se proponen para establecer una particular relación con sus destinatarios/receptores, que supone cierto verosímil y ciertos recorridos de interpretación".

En este marco se parte del supuesto que "(...) el discurso es el lugar de construcción del sujeto. A través del discurso el sujeto construye el mundo como objeto y se construye a sí mismo" (Lozano,1999:72). En la relación dialógica presente en los textos, es donde docentes y alumnos a distancia, se 
constituyen como sujetos activos del proceso educativo. Cabe señalar que en la producción textual como objeto semiótico se debe tener en cuenta tanto el sistema como el proceso, elementos que son constitutivo de la lengua, y que adquieren significación cuando son actualizados en la enunciación. En los textos de educación virtual que se analizan es de interés indagar la articulación de las formas enunciativas que dan cuenta de las personas, espacio, tiempo y situaciones en un contexto de enseñanza-aprendizaje caracterizado por la no presencialidad que son construidos por el texto que es mediado por un soporte electrónico.

Leonor Arfuch (1999:44) plantea los siguientes interrogantes que podemos hacer extensivos a la propuesta de educación virtual:

¿Cómo leer, comprender, percibir, experimentar- de la 'misma' manera? ¿Cómo otorgar a un mensaje el 'mismo' sentido que lo inspiró? Porque el sentido no es algo inequívoco, que viene dado en la forma del mensaje, verbal o visual. Más bien es algo que se negocia, producto de una tensión entre la significación que el texto (la imagen) propone y la apropiación que realiza el destinatario o receptor. Esta tensión es la que lleva a otro desplazamiento: el de la posición central del enunciador. La idea de negociación (intercambio, interacción) supone la existencia de partenaires, copartícipes de un proceso activo y continuo de significación donde en verdad no es posible separar un 'primero' (el enunciador) de un 'segundo' (el destinatario): sólo porque existe este último, otro capaz de comprender, tiene lugar el mensaje, aunque este otro no sea más que una figura imaginaria, un desdoblamiento, otro yo.

\section{La construcción de la comunicación en el Campus Virtual Puntoedu}

Al introducirnos en el reconocimiento de las formas enunciativas de la propuesta comunicativa del Campus y Aula Virtual se puede reconocer que la enunciación discursiva corresponde mayormente a las formas propias de la comunicación oral, ya que se intenta crear una idea de presencialidad tanto con respecto a lo espacial como a lo temporal en donde el docente y el alumno se encuentran en un contexto virtual compartido, como dice el texto de presentación institucional de Puntoedu (2002-2007) y como se muestra a continuación:

"Puntoedu se presenta como una propuesta innovadora de educación a distancia destinada a la formación y actualización profesional. Utilizamos como ambiente de aprendizaje el soporte web, potenciando las posibilidades que ofrece Internet.

Estas tecnologías permiten superar las restricciones espacio-temporales, favoreciendo la adaptación de los procesos de enseñanzaaprendizaje a los ritmos, posibilidades y tiempos personales (...)"

La referencia temporal no sólo se realiza a través de la expresión "superar las restricciones espacio-temporales", sino también por medio de los tiempos 
verbales, en el caso del presente es utilizado para situar el hecho educativo como contemporáneo a la enunciación, es decir como si estuvieran compartiendo el "ambiente" como metáfora de la institución o el aula dando una clase.

\subsection{El aula como entorno virtual de aprendizaje y comunicación}

La propuesta didáctica de las diferentes ofertas de cursos de Puntoedu se organiza a partir del espacio virtual denominado "aula virtual" en el que se conjugan coordenadas temporo -espaciales dando origen a un ambiente de encuentro para realizar actividades que conducen al aprendizaje en la Web. Este es un espacio abierto en formato hipertextual que se encuentra conectado a Internet potenciando el uso de los recursos de la red. El aula conforma un entorno en donde se articulan las actividades involucradas en el proceso de enseñanza y aprendizaje en línea; como así también cuestiones de gestión administrativa que se presentan a través de la interfase que dispone de íconos y menúes de acciones que posibilitan la interacción con el entorno, donde se tiende a proponer las modalidades de acción directa sobre los objetos (íconos que representan herramientas de comunicación, carpetas de archivo, impresora, etc.) que permiten simular el diálogo que enmarca tanto visual y conceptualmente la acción sobre las imágenes y selecciones operadas por el usuario.

El diseño de esta interfase gráfica contribuye a la creación simbólica de la metáfora del "aula" que permite la manipulación de datos, textos, voz, imagen, sonido y la interactividad comunicativa mediante el foro, chat, correo electrónico; en que los límites de tiempo y espacio se desdibujan. En su forma de organización y su metodología de interactividad radica su potencial, que modifica los procesos de enseñanza y aprendizajes tradicionales.

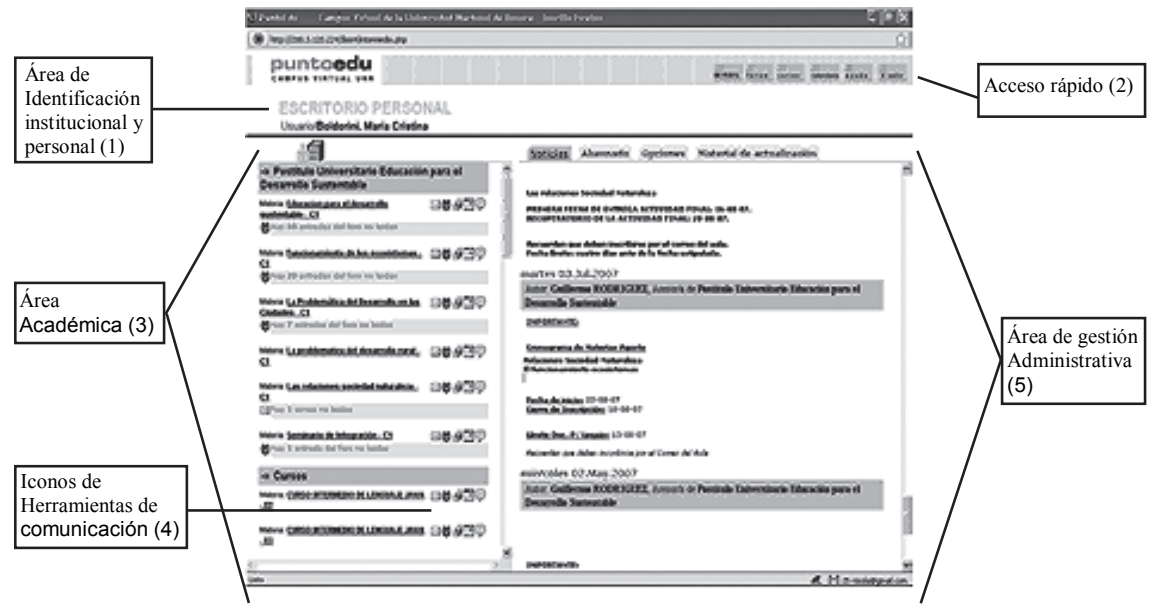

Gráfico 1: Interfase Escritorio del Aula Virtual 
El Alumno, Tutor o Asesor al ingresar, mediante la utilización de una contraseña, se encuentra con la interfase, lo que se denomina "Escritorio Personal". Esta interfase del escritorio presenta diferenciaciones entre los perfiles del usuario, según sea Asesor, Tutor, Alumno, respondiendo a la virtualización de los roles que desempeñan y a las actividades que realizan en el entorno virtual. La observación de la interfase permite reconocer en la parte superior el Área de identificación institucional y personal (1) con el logo y nombre del Campus situando al usuario en el ámbito institucional del que forma parte y personalizando su espacio a través de la inscripción del nombre del usuario y su rol en la comunidad de aprendizaje. Esto pone en juego los procesos de desterritorialización y localización característicos de la virtualidad creando una espacialidad que une lo digital con la estructura física, integrando al usuario como sujeto parte de esta comunidad institucionalizada en la que se producen intercambios, negociaciones, acciones de diverso orden que permiten la construcción social del conocimiento.

Además presenta en el sector izquierdo un menú de Botones de acción (2) que dan lugar al acceso al espacio de "Mi perfil" , "Foro", "Correo", "Ayuda", "Salir" que posibilita una navegación rápida hacia estos recursos. El botón de "Ayuda" abre una pantalla que conecta con el correo electrónico del Servicio Técnico, al que le pueden solicitar asesoramiento sobre las dificultades que se le presentan sobre el manejo de la plataforma o algún programa que sea necesario utilizar.

En "Mi perfil" se despliega una interfase con la opción para cambiar la contraseña que le otorga el sistema, lo que garantiza la privacidad. La observación de este espacio en plataformas de e-learning tales como Web-CT, Educativa, El Príncipe, Moodle, muestra que los usuarios tienen la posibilidad de publicar su fotografía acompañada de un breve relato de sus características personales, facilitando la conformación de la comunidad virtual. En Puntoedu, esta estrategia comunicativa, es tratada de suplir con la propuesta del correo de presentación en el inicio de cada curso o materia de acuerdo a lo expresado por los Asesores.

En la parte inferior izquierda separada por una línea horizontal de la zona de identificación personal e institucional, se despliega el Área Académica (3) destinada a actividades de enseñanza y aprendizaje permitiendo el ingreso al espacio que organiza las Clases de las diferentes materias por carrera o cursos en los que participa cada uno de los usuarios. En la parte contigua a la denominación de cada una de las materias, se encuentran los íconos (4) que corresponden a las herramientas de comunicación para acceso rápido sin necesidad de entrar al contenido de las clases.

En la parte inferior derecha se dispone de un Área de Gestión Administrativa (5) donde se despliega un menú de acciones con "Noticias" que aparecen organizadas por fechas de publicación organizando la temporalidad del grupo; 
esta opción está únicamente habilitada para Tutores y Asesores y es utilizada para dar a conocer información sobre inscripciones y exámenes, avisos que revistan importancia de carácter administrativo, saludos generales para fechas de finalización de cursos, fiestas que conmemoran acontecimientos como Navidad, Año Nuevo, Día del Trabajador.

En este área también está presente la parte destinada a "Alumnado" que pone a disposición del Alumno el formulario digital de inscripción de alumno regular de la U.N.R., similar al de la oferta educativa presencial. A continuación, el botón de "Opciones" le ofrece programas utilitarios para poder trabajar en el entorno educativo y en "Materiales de Actualización" encuentran bibliografía y nuevos materiales de lectura aportada por los tutores.

\subsection{La comunicación en virtualización de las clases}

El proceso de enseñanza y aprendizaje está organizado en clases virtuales que presentan desarrollo de los contenidos, bibliografía, consignas de los profesores, actividades de aprendizaje, actividades de evaluación y de autoevaluación, correo electrónico para el asesoramiento de los tutores y comunicación entre estudiantes en el mismo entorno virtual, chats con encuentros semanales en tiempo real de tutores y alumnos, foros en forma asincrónica, calendario académico dispuesto para cada curso.

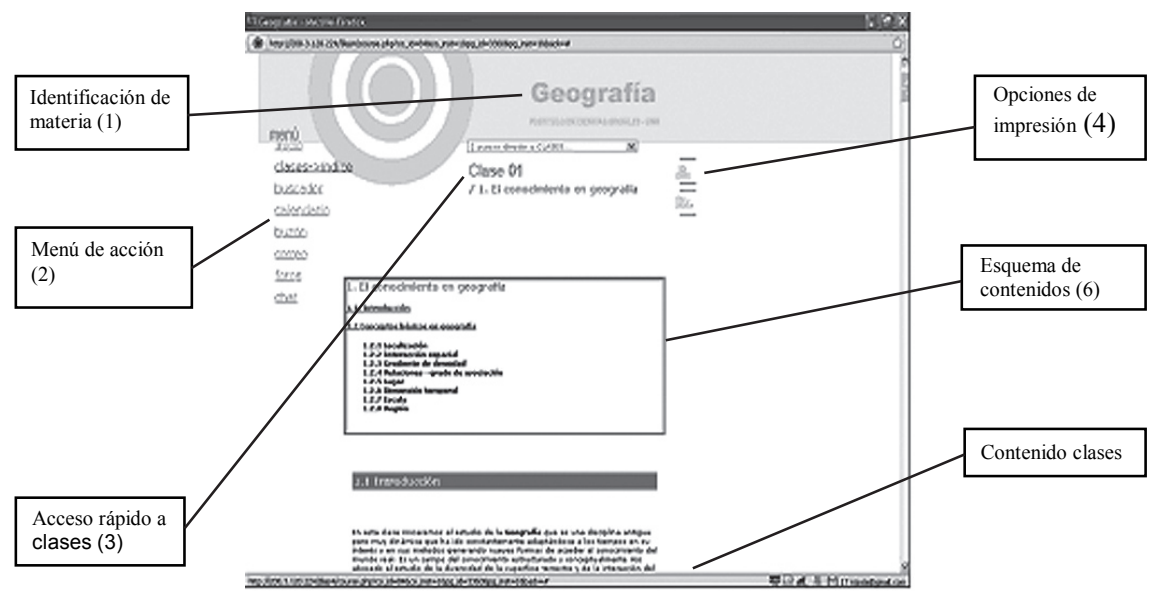

Gráfico 2: Interfase Clase Virtual

En esta interfase se repite el diseño del "Escritorio", ya que presenta en su parte superior el logo de la identificación institucional del Campus y la denominación del curso o materia, el tema y número de la clase, introduciendo al usuario de este modo en el espacio curricular. En el sector inferior izquierdo se encuentra el Menú de acción (2) que les posibilita el acceso rápido al Escritorio 
a través del "Inicio" y a las diferentes herramientas de comunicación, búsqueda y clases; en el botón (3) también se da un link de acceso al esquema de clases y actividades. En el centro se encuentra el esquema de contenidos de la Clase, en el que cada uno de los ítems del mismo funciona como hipervínculo que relaciona con el apartado seleccionado. A continuación aparece el desarrollo de los contenidos.

La descripción del Aula y de Clases Virtuales que se ha realizado indica que si bien los entornos virtuales se caracterizan por la desterritorialización, en la metáfora del Escritorio con que se organizan estos espacios, se puede reconocer las marcas de territorio digital que comparten aquellos que son miembros de la misma, que se produce en el diseño hipertextual de la interfase gráfica dando lugar a una navegación dinámica mediante la manipulación de los objetos del menú de acciones e íconos que permite virtualizar actividades de la educación presencial en el entorno digital. En esta manipulación de objetos es donde se establece un proceso de interacción dialógico entre el operador y la interfase áulica; por un lado es un texto estructurante o modelizador, que contiene un número limitado y prefijado de modalidades morfogenéticas y por el otro la interpelación del operador que actualiza los posibles vínculos que le ofrece.

\subsubsection{La comunicación dialógica en el diseño de contenidos}

El diseño de los contenidos de las clases está a cargo de los docentes contenidistas quienes ponen en juego las estrategias de enseñanza y aprendizaje que permiten establecer la interactividad entre alumno - texto, profesores - estudiantes y estudiantes - estudiantes, para la construcción de conocimientos significativos. En los textos se puede reconocer la intencionalidad de establecer una comunicación dialógica con los alumnos, hecho que se evidencia en su redacción donde incluyen la presencia discursiva del docente. La redacción del contenido es un aspecto relevante en un programa a distancia ya que establece el modo de relación institución - docente - alumno, generalmente construido en base a los textos y actividades propuestas, complementado con la acción tutorial.

La elaboración de los contenidos presenta un desarrollo de los temas en formato electrónico hipertextual articulándolo con bibliografía, sitios webs, imágenes sobre el tema. En la redacción de los contenidos, la presencia del docente se reconoce en los enunciados, por el modo en que establece un diálogo con el alumno propiciado a través de la utilización de explicaciones, comparaciones, síntesis, recapitulaciones, promoviendo el desarrollo de procesos cognitivos.

En la redacción de contenidos se utilizan los deícticos "nosotros" para indicar la presencia del docente y "ustedes" para establecer la relación dialógica con los alumnos, como presentamos en el siguiente ejemplo:

"En este punto es interesante que volvamos a pensar lo dicho en la primera clase, respecto de las diferentes propuestas de desarrollo capitalista. Es probable que Ustedes deban retroceder y repensar, 
por ejemplo, el modelo cepalino, o el menos elaborado modelo de Rostow. Estos especialistas -desde entonces llamados los "tecnoburócratas"- tuvieron una participación directa en los gobiernos latinoamericanos (...)" (Clase de Historia Puntoedu 2005).

Los deícticos, que definen la identificación y la localización de las personas, objetos, procesos, acontecimientos y actividades, establecen relación con el contexto del acto de enunciación (pronombres personales y demostrativos, adverbios y el tiempo verbal, como "nosotros" y "ustedes" reenvían obligatoriamente al mensaje, implicando una referencia al proceso de enunciación.

Además la persona del verbo caracteriza protagonistas del proceso del enunciado. El nosotros representa uno de los protagonistas del proceso del enunciado con el agente del proceso del enunciado. La relación que se establece entre "nosotros" y "ustedes" representa una correlación de subjetividad. El "ustedes" se presenta como un no-nosotros, la persona no subjetiva, diferente del "nosotros". En este caso "nosotros", representa a los docentes que diseñan el módulo de contenidos a distancia, es decir al que enuncia (sujeto de la enunciación) el discurso a través de estos textos que tienen una finalidad educativa. Éste permite construir una relación dialógica entre el "nosotros" y "ustedes", involucrándolos en el sentido de temporalidad compartida; al igual que cuando se hace referencia a lo temporal "volvamos a pensar lo dicho en la primera clase".

Hasta aquí nosotros hablamos de la relación teoría-datos y dejamos de lado, deliberadamente, la cuestión de la adecuación de las teorías, que pondríamos ahora en aquel lugar que hace posible la especificación de esa relación. Dicho de otro modo, la adecuación puede entenderse como la lectura que resulta del modo registrado en niveles en que entran en relación los elementos de la serie observación-teoría-datos (...) (Clase Teoría Política 2006).

A la referencia discursiva del par "nosotros" y "ustedes" le acompañan otros deícticos que se refieren al "nosotros" permitiendo la localización espacial y temporal que es coextensiva y contemporánea a la situación discursiva que contiene el "nosotros". Si bien como expresa Lozano:

"(...) la característica importante de este tipo de signos, el que su función localizadora se da exclusivamente en situaciones de comunicación oral, tipo de conversación cara-a-cara, pero que todo tipo de textos, incluidas conversaciones, son usadas con las otras formas enunciativas, para construir enunciaciones representadas, para permitir los actores modular de diversas formas de su participación en el enunciado, crear tiempos y espacios superpuestos e indicar relaciones interlocutivas (...)" (Lozano,1999:100)

En la presentación de los cursos aparecen ejemplos del uso de deícticos que permiten la representación espacial estableciendo las posiciones del locutor que remite al lugar de la enunciación: 
"Este curso ha sido diagramado en función de satisfacer demandas de los profesores de la EGB y el Polimodal, a partir de las modificaciones implementadas por la Ley Federal de Educación." (Presentación institucional de Puntoedu 2002-2007)

La referencia temporal no sólo se realiza a través de los deícticos sino también por medio de los tiempos verbales, en el caso del presente es utilizado para situar el hecho educativo como contemporáneo a la enunciación, reforzado adverbios de tiempo, es decir como si estuvieran en un aula dando una clase, por ejemplo:

"Comenzamos hoy con el desarrollo de la materia Análisis del Discurso integrada al Postítulo de Formación Universitaria en Lengua y Literatura en el contexto del Programa de Educación a Distancia, Puntoedu, de la Universidad Nacional de Rosario." (Clase Análisis del Discurso Puntoedu 2006)

"Los tutores somos docentes que diseñamos el curso, nuestra tarea va más allá de la simple respuesta a una pregunta, estamos para asesorarlos y orientarlos en relación a los contenidos, bibliografía y actividades propuestas. Les proponemos, para un mejor aprovechamiento de este espacio, que ustedes organicen sus mensajes indicando la unidad y el tema sobre el que desean consultar." (Texto de presentación de Tutores Puntoedu)

La utilización del tiempo pretérito perfecto representa la forma autobiográfica, estableciendo una conexión entre el acontecimiento pasado y el presente en que se sitúa una evocación y una relación entre el sujeto y los hechos que habla.

“(...) Retomamos por último la distinción entre Teorías tipo A y Teorías tipo $B$ que habíamos hecho más arriba podríamos decir que en relación a los niveles de adecuación, las Teorías Tipo A conllevan una restricción inicial impuesta por el método y la teoría misma. Así la adecuación alcanzada, dado el objetivo prefijado, es la descriptiva, mientras que las Teorías Tipo $\mathrm{B}$ alcanzan, también en relación a su objetivo, la adecuación explicativa (...)" (Clase Análisis del Discurso Puntoedu 2006).

El tiempo futuro es utilizado en la enunciación de las "Actividades", implica una obligación una certeza y no se caracteriza tanto por el tipo de localización temporal sino por las modalidades subjetivas que implica.

"Ahora les proponemos que lean con mucha atención lo que al respecto señala Luis Romero (...), y luego le aconsejamos, se interroguen sobre el mismo, busquen otras explicaciones en el texto de(...). Tal vez ahora estarán en mejores condiciones de comprender este complejo entramado de nuestra 
historia y podrán realizar los ejercicios que les ayudarán a construir su universo explicativo." (Clase de Historia Puntoedu 2006)

Además, los textos que aparecen a lo largo del desarrollo de las clases, como el anterior, se caracterizan por ser discursivos, personalizados, modelizados a través de los modos verbales, las expresiones modales que indican tiempos comentativos, interrogaciones y la relación interlocutiva del texto. Las categorías verbales, adverbiales, pronominales configuran el texto permitiendo reconocer las marcas de subjetividad que se dan en el mismo de temporalidad compartida por los actores del proceso enseñanza aprendizaje.

Cabe señalar que todos los textos no se dan en forma pura como subjetivo u objetivos, aunque prevalezcan uno sobre otro, sino que se producen cambios pasando del texto subjetivado al objetivado o viceversa, estos procedimientos que se realizan a través de localización espacial y temporal y de las formas de personalización o despersonalización del discurso.

En la materia Lingüística se presenta el siguiente texto:

"Una vez que hemos caracterizado el lenguaje humano, retomemos entonces, qué significa incluir a la teoría lingüística en un programa de investigación. Para esto es necesario antes que tengan claro qué se entiende por "programa de investigación". [enunciación discursiva subjetivada]

"La noción de programa de investigación (P.I) parte de Lakatos quien considera a las teorías como estructuras organizadas de algún tipo. Deben ser estructuras sin límites que sirvan de guía a la futura investigación (...)" [enunciación objetivada]

En la enunciación subjetiva se puede identificar una personificación del sujeto de la enunciación: narrador, en la forma del nosotros de docente-autor reconocida por la terminación del verbo. En cambio en la enunciación objetivada, no aparece ningún "nosotros", en este proceso de conmutación se borra la figura del narrador, que en este caso se da a través del cambio de tiempos verbales. Es decir la figura del sujeto de la enunciación (enunciador) se borra tras un discurso despersonalizado, pero éste pertenece al texto y es delimitado por el texto. Como expresa Lozano:

“(...) desde los contenidos de que el texto habla __provienen de un hacer semántico que dota de cierta existencia a ciertos objetos, que serán también axiologizados y moralizados _ hasta la organización temporal y espacial _ que referencializa los acontecimientos _ la elección de un nivel de inteligibilidad, o las estrategias discursivas puestas en marcha, emanan y remiten al enunciador textual..." (Lozano,1999:113)

Los modos en que se expresa el enunciador en un texto implica la representación de un destinatario; un "nosotros" [en el caso que estamos anali- 
zando] implica la concepción de un "ustedes". Este destinatario del texto es el enunciatario que establece un contrato enunciativo junto al enunciador, quien articula aspectos cognitivos, persuasivos, que le permiten construir a nivel semántico y modal la enunciatario. Esto es tenido en cuenta por U. Eco cuando desarrolla la concepción de "Lector modelo". El enunciador, Autor para Eco, recurre a diferentes medios para caracterizar a un Lector modelo en cuanto al uso de la lengua, de determinado léxico, las marcas estilísticas, es decir que también lo construye.

Los textos que presentan las "Actividades" de los cursos están formulados con la utilización de imperativos, que no implican necesariamente un deber hacer del enunciatario o lector modelo, sino que establece un contrato para que el alumno de estos cursos ponga en juego su saber-hacer que implique la adquisición de los contenidos desarrollados:

"1. A partir de la lectura del artículo de Juan Carlos Portantiero, "Economía y política en la crisis Argentina", redacten un texto donde caractericen las distintas fuerzas sociales y políticas que protagonizaron el empate hegemónico.

2. Describa la contradicción esencial que separaba a agrarios e industriales y explique la relación entre la crisis de la balanza de pagos y distintos intereses de la burguesía agraria industrial." (Clase Teoría Política Puntoedu 2006).

De acuerdo al análisis realizado sobre el modo de construcción de los textos de las clases se reconoce que se caracterizan por ser personalizados, modelizados a través de las formas verbales en primera persona del plural para la figura del docente y segunda persona del plural para los alumnos, además las expresiones modales que indican tiempos comentativos, interrogaciones y la relación interlocutiva del texto. Las categorías verbales, adverbiales, pronominales configuran el texto permitiendo reconocer las marcas de subjetividad que se dan en el mismo. La enunciación discursiva corresponde mayormente a las formas propias de la comunicación oral, tipo de enunciación que intenta crear una idea de presencialidad tanto con respecto a lo espacial como a lo temporal en donde el docente y el alumno se encuentran en un contexto virtual compartido.

\subsubsection{La comunicación entre alumnos, tutores y asesores}

El análisis del espacio de comunicación entre los diferentes actores que participan de la propuesta es posible gracias a la disponibilidad de los informes cuantitativos y cualitativos del Campus virtual Puntoedu.

El espacio de comunicación se construye con la inclusión de las herramientas de comunicación: correo, chat, foro que utilizan la escritura para mensajes asincrónicos o la escritura oralizada sincrónica. En este apartado se analizan no 
sólo el modo de difusión o intercambio de mensajes, sino que da cuenta de las modalidades de interacción alumno-tutor, alumno-alumno, uno-todos mediante los cuales se lleva a cabo el proceso de reconocimiento entre los individuos, cómo éstos se producen, modifican o negocian significados, contribuyendo a la conformación del entramado simbólico educativo.

"El profesor era muy amigo, el tema de la enseñanza, de enseñarte, no tiene inconvenientes, yo me sentí muy conforme con el profesor, de profesor y alumno terminamos siendo amigos, creo... (risas), Da un poco de risa pero es así... solía mandarle muchos correos." (Entrevista a alumno de la materia Educación Desarrollo Sustentable 2007)

\subsubsection{El correo electrónico}

El correo que ofrece comunicación asincrónica es la herramienta más utilizada por la comodidad y la facilidad, los alumnos manifiestan que al no requerir de días ni horarios en particular, y por la rapidez y la especificidad en la respuesta del tutor, es el más adecuado para establecer relaciones con los demás. Los datos muestran que existen diferencias con respecto a la frecuencia en la utilización, donde se destacan los alumnos de los postítulos de formación docente cuyo promedio de consultas supera ampliamente a las que realizan los alumnos de la tecnicatura y de los cursos; generalmente sus intervenciones tienen que ver con dudas sobre el modo de uso y potencialidades de herramientas de la plataforma, contenidos y comentarios sobre cuestiones personales. Muchos de ellos manifiestan que realizan dos aprendizajes simultáneos, uno en relación a la especifidad de temas y otro con respecto a la adquisición de competencias tecnológicas.

El diseño de la interfase del correo presenta similares características al diseño de correos de WebMail, pero se diferencia por ser cerrado ya que solamente habilita la comunicación entre los tutores, alumnos y asesores, permite del envío de mensajes al grupo y a otros estudiantes en forma individual, y entre alumnos; esto favorece la interacción entre los diferentes actores que participan de la experiencia educativa virtual, lo que facilita la construcción de un espacio de comunicación público y otro privado. En el cuerpo del mensaje aparecen siempre la fecha y hora de emisión del mismo, dando lugar a marcas de temporalidad compartida entre los usuarios; las interacciones se dan en tiempo real, que en este caso es diferido pero que al presentar las marcas discursivas permite un sentido de continuidad de acción a pesar de la duración discontinua, aparece la sincronización como característica en la construcción de la temporalidad.

El contenido de los mensajes no sólo se limita al planteo de dudas; en el caso de los alumnos de las carreras circulan mensajes sobre cuestiones personales, hechos que refieren a su vida cotidiana, en muchos casos se han establecido relaciones amistosas que se continúan una vez finalizado el cur- 
sado. Al inicio del cursado los asesores realizan un primer contacto a través del correo de bienvenida:

"Hola a todos!!

Bienvenidos al aula virtual de Puntoedu. Para los estudiantes que no nos conocen, somos Julia Trujillo y Mariano Diodati, asesores del Postítulo Universitario en "Educación para el Desarrollo Sustentable".

Les sugerimos que para poder ir conociéndonos, cada uno de ustedes se presente. Comenzamos nosotros:

Julia: Soy de Rosario, Lic. en Comunicación Social, docente de la Universidad desde 1994, y siempre me he preocupado por la relación entre los medios y la educación...

Mariano Diodati. Soy de Rosario, Prof. y Lic. en Ciencias de la Educación, docente de carreras universitarias y de una Escuela de Enseñanza Media para Adultos...Nos podrán encontrar siempre en el correo ASESOR DE LA CARRERA.

Esperamos sus presentaciones a través del correo. Saludos. Buen fin de semana." (Correo Educación Desarrollo Sustentable)

Al igual que en los textos institucionales y del desarrollo de los contenidos de las clases, la comunicación dialógica se plantea en relación a la referencia discursiva del par "nosotros" y "ustedes" acompañada por otros deícticos que se refieren al "nosotros" permitiendo la localización espacial y temporal que es coextensiva y contemporánea a la situación discursiva que contiene el "nosotros". Existen además referencias al tiempo como organización de actividades para los miembros de la comunidad.

En el contenido de los correos se pueden reconocer características de los textos orales, como la reiteración de la utilización de los tiempos presentes, la utilización de la primera y segunda persona gramatical, marcas espacio- temporales mediante la utilización de formas adverbiales, escasa utilización de disyuntores discursivos (sin embargo, a pesar de ...), pero sí la utilización de nexos de coordinación, modalidades de saludo que tienen que ver con los modos de comunicación cara a cara como "hola", incluso si aún no se conocen, formas que remiten a un tiempo y espacio compartido. Estos recursos enunciativos juegan a modo de estrategias comunicativas, a modo de compensación de la ausencia de la gestualidad que se da en la comunicación cara a cara, que le advierten al enunciatario ciertas intencionalidades del enunciador.

\subsubsection{El Chat}

Para el estudio del modo de apropiación de esta herramienta, se han realizado entrevistas a los alumnos sobre las significaciones que le atribuyen 
a su uso; en la siguiente etapa profundizaremos sobre el análisis de un corpus de contenido de chats de carreras y cursos.

El chat del aula de Puntoedu, sólo es abierto a la comunidad virtual de aprendizaje, la interconexión se lleva a cabo en forma textual; los tutores y alumnos se comunican en tiempo real pero están situados en territorios geográficos diferentes; situación que posibilita compartir un continuo que va del territorio geográfico a un espacio compartido virtual común, que crea la noción de territorio compartido a través del diálogo más allá del proceso de desterritorialización que implica estar comunicados en estos entornos.

Los textos en general están limitados por la rapidez con que se deben escribir los enunciados en tiempo real; en general los participantes presentes en el salón mandan mensajes y leen los mensajes de todos los presentes. También está habilitada la opción de mantener una charla privada entre los miembros del grupo.

En las entrevistas realizadas a los alumnos esta herramienta de comunicación es identificada como espacio de comunicación sincrónico en donde se aclaran dudas, se realizan comentarios y valoraciones acerca de la marcha del curso o carrera y se conversa sobre cuestiones personales y sociales. En el caso de las carreras, los alumnos acuerdan horarios de encuentro sin la presencia del tutor para realizar actividades y consultas, es un modo de organizar el estudio en grupo mediado por la computadora.

Algunos de los alumnos manifiestan que no le parece provechoso el diálogo con otros compañeros del Curso puesto que pueden "confundirlo" al brindarle una respuesta errónea a sus inquietudes y que se le dificulta la lectura debido a la fragmentación del discurso ya que no siempre las respuestas aparecen en un orden secuencial a las preguntas. Los enunciados normalmente aparecen en forma yuxtapuesta, convergiendo sin orden en el salón, cuestión que puede plantear dificultades interpretativas para los usuarios.

Los alumnos de los Cursos de Informática destacan la escasa participación debido a que los horarios de los mismos no son flexibles. Sin embargo, el uso de esta herramienta es señalado como "provechoso" justamente cuando el número de participantes es bajo y se puede consultar de manera más ágil con el tutor.
“(...) teníamos que esperar a los jueves en el horario del chat, en principio éramos varios después fuimos quedando unos pocos en el chat, entonces ya era más fácil a veces consultar, así y todo a veces se cruzaban un poco las preguntas con las respuestas y demás." (Entrevista Proyecto Diseño Web Puntoedu 2006).

En el caso de las carreras, la mayoría de los alumnos reconoce su utilidad para despejar dudas, consultar con los tutores o hacer comentarios acerca de diferentes temas. Los alumnos de los postítulos que no participan porque no coinciden en el horario o por motivos laborales, manifiestan que les resulta muy 
útil el hecho de poder contar con la publicación de las sesiones ya que pasa a formar parte de sus materiales de estudio.

"Me resultó sumamente útil que publicaran el Chat y lo mandaran por mail porque uno por ahí en ese horario quedó justo ocupado o había materias que tenían el Chat en momentos que yo estaba trabajando entonces cuando el Chat se publicaba lo leía y después me comunicaba por mail." (Entrevista alumno Lengua y Literatura Puntoedu 2006).

A partir de los comentarios de los alumnos, tanto de las carreras como de los cursos de Informática, se observa que en muchas ocasiones el espacio del Chat es utilizado por los alumnos para efectuar consultas con el tutor sin interactuar con el resto de sus compañeros. Es decir, en el Chat se reproduce la lógica de interacción del correo. Este aspecto, sumado a que en ciertas ocasiones la extensión de lo que se escribe no se corresponde con la inmediatez que requiere esta herramienta (sino más bien con otras como el foro, weblogs), genera dificultad para comunicarse, favorece el "monopolio" de las intervenciones por parte de algunos alumnos y en detrimento de la participación de los demás, se agranda la brecha entre las preguntas, las respuestas, los temas.

Los alumnos valorizan la posibilidad de disponer el contenido del Chat, para poder imprimir y leer los temas tratados, esto evidencia como hay toda una tradición con respecto al texto impreso, aunque la estructura discursiva de los chats responde al modelo de la comunicación oral, coloquial, tiene que ver también con la falta de hábito en su uso en la vida cotidiana, como lo hacen los jóvenes y adolescentes.

"Participo poco de los Chat, me parece que por ahí como que no me resuelven demasiadas cuestiones (...) como que hay mucha gente hablando al mismo tiempo y el hecho de no tener la mirada en el otro como que se dificulta, todo el mundo pregunta, todo el mundo responde, otra le contesta a otro, entonces para mi era una pérdida de tiempo... yo los leo porque el hecho de que te los manden te permite hacer una lectura general." (LyL - Entrevista Puntoedu 2006)

En esta primera aproximación al estudio del Chat se reconoce una nueva forma de comunicación que se caracteriza por la informalidad del estilo comunicacional de la conversación oral; Francisco Yus lo denomina "texto escrito oralizado". El hecho que la comunicación sea en tiempo real permite una continuidad de acción a pesar de la duración discontinua; la sincronización reemplaza la unidad de lugar y la interconexión sustituye la unidad de tiempo creando la idea de una temporalidad compartida.

\subsubsection{EI Foro}

Este es el espacio de participación que convoca a todos los integrantes del Aula virtual a realizar aportes para promover la construcción del conocimiento 
colectivo sobre las temáticas abordadas en las clases. La apertura de los foros la puede proponer el tutor o cualquiera de los alumnos que deseen plantear un tema de discusión, la ventaja de esta herramienta es su carácter asincrónico que permite reflexionar y producir textos de mayor profundización que el que se puede desarrollar en el Chat por su instantaneidad.

De varios testimonios surgidos en las entrevistas se deduce cierto desconocimiento en cuanto a las características del foro. Varios de los alumnos entrevistados reconocen que no participan en este espacio porque no saben cómo utilizar esta herramienta. Algunos mencionan que son los docentes quienes crean pocas situaciones para que se dé la participación.
"(...) al que le dimos muy poco uso fue el foro, me hubiera gustado que todas las materias le den más trabajo, o sea, el tema de salir a debatir, de salir a plantear algo y que los demás opinen, por eso el de teoría política fue el mejor porque hubo opiniones encontradas y eran idas y venidas y respuestas, siempre con altura. Opiniones que no nos poníamos de acuerdo, yo opinaba totalmente distinto que una chica que era la que más opinaba, entonces escribía cada uno con su idea, obviamente, yo no quería convencer a nadie y ella tampoco, y los demás tampoco, pero es interesante porque si bien no es eva- luativo, te deja abrir el juego y decir "yo no pienso como vos o yo sí pienso como vos y aparte agrego esto", y eso se da en el foro. Por- que en el chat, si vos estás conectado en el momento lo podés decir, pero y si no estás conectado ?" (Entrevista alumno Economía)

Los modos de apropiación de esta herramienta difieren de acuerdo al perfil de los alumnos; en el "Curso de Diseño Web" es utilizado para la presentación de proyectos, lo que permite que todos los alumnos puedan acceder a las propuestas de los compañeros y a las correcciones que realizan los tutores; en los Cursos de Informática los alumnos lo utilizan como una especie de pizarra donde plantean las consultas sobre contenidos y los tutores responde a las dudas, todos los alumnos acceden a las mismas. En estos cursos, aunque los alumnos tienen mayores conocimientos en informática, se observa una menor comunicación a través del correo que en las materias o cursos de ciencias sociales, educación para el desarrollo sustentable y administración, donde los participantes manifiestan dificultades para el uso instrumental de la plataforma.

EL análisis del espacio destinado a la comunicación del entorno educativo muestra las diferentes herramientas que posibilitan la interactividad mediada por los ordenadores, dando lugar a la participación de una pluralidad de actores que promueve la interactividad social, la conformación de una comunidad educativa y la construcción del conocimiento.

Esta interacción social es espacial ya que los diferentes usuarios lo navegan, recorren, pero sin olvidar que esta espacialidad virtual es construida por las distintas formas que propician y por las construcciones discursivas de los 
participantes. Las referencias discursivas del tiempo y espacio virtualizado y mediadas por el entorno tecnológico ponen en juego la relación de la unidad de tiempo sin unidad de lugar favoreciendo la continuidad de acción a pesar de la duración discontinua por lo que la sincronización reemplaza la unidad de lugar y la interconexión a la unidad de tiempo.

\subsection{Algunas consideraciones para repensar la comunicación en la educación virtual}

A modo de reflexiones finales, lo expuesto anteriormente permite reconocer que en los entornos educativos virtuales la comunicación entre los diferentes actores del proceso de enseñanza y aprendizaje se produce a través de la construcción discursiva que se propicia en los ambientes de la clase y en especial en los contenidos y las herramientas de comunicación. Esto es posible visualizarlo en la producción de los textos educativos donde el docente se constituye como tal y establece una relación dialógica a través de los textos donde el estudiante construye su objeto de aprendizaje y se constituye como sujeto activo en este proceso. Para esto se recurre a formas enunciativas que dan cuenta de las personas, la construcción del espacio, tiempo y situaciones educativas en un contexto de enseñanza y aprendizaje.

En la propuesta de educación virtual de Puntoedu, la comunicación es uno de los aspectos centrales, ya que su diseño hace eje en el proceso de producción de sentido con el intercambio en los roles discursivos entre alumnos y docentes; a lo que se les suman los modos de interactividad que posibilitan las herramientas de comunicación online u offline que dispone el entorno. El espacio de comunicación con la inclusión del correo electrónico, chat y foro, propicia interacciones entre todos los miembros de la comunidad educativa en tiempo real y asincrónico, permite la emergencia de un nuevo modelo que favorece la socialización en forma pública y privada entre los diferentes actores. Esto da lugar a la construcción de un tiempo y un espacio virtual que es compartido más allá de los muros de la institución, en los que es posible el proceso de reconocimiento entre los individuos y la negociación de significados, que contribuyen a la conformación del entramado simbólico educativo.

\section{Referencias Bibliográficas}

- Arfuch, L. (1995) "El diseño en la trama de la cultura: desafíos contemporáneos" en Diseño y Comunicación. Teoría y enfoques críticos. Buenos Aires.

- Burbules, N. y Callister, T. (2001) Educación. Riesgos y promesas de las nuevas Tecnologías de la información. Ed. Granica. España.

- Levy, P. (1999) ¿Qué es lo virtual? Ed. Paidós. Barcelona.

- Lozano, Peña (1999) Análisis del discurso. Hacia una semiótica de la interacción textual. Ed. Cátedra. Madrid. 
- Tiffnin J., Ragasingham, L. (1997) En busca de la clase virtual, la educación en la sociedad de la información, Ed. Paidós, Barcelona, Bs. As. México.

- Vilches, L. (1997) La lectura de la imagen. Prensa, cine, televisión. Paidós. España.

- Zapata Ros, M. (2001) Formación abierta y a distancia a través de redes digitales: Modelos de redes de aprendizaje. Extraído el 23 de agosto 2003 en

- http://www.um.es/ead/red/1/modelos.pdf. 